\title{
Performance Analysis of Table Driven and Event Driven Protocols for Voice and Video Services in MANET
}

\author{
Haque Nawaz ${ }^{1}$, Dr. Hasnain Mansoor $\mathrm{Ali}^{2}$ \\ ${ }^{1,2}$ Shaheed Zulfikar Ali Bhutto Institute of Science and Technology (SZABIST) Karachi, Pakistan \\ ${ }^{1}$ lashari.haquenawaz@gmail.com \\ 2 husnain.mansooreszabist.edu.pk
}

\begin{abstract}
This research paper encompasses the performance analysis of table driven and event driven routing protocols by using voice and video traffic in mobile Adhoc network (MANET). Particularly, OLSR (table driven) and DSR (Event driven) protocol are considered. The nodes of MANET establish the connections with each other energetically and can move freely in any direction. In mobile Adhoc network, environment event driven and table driven protocols have significant subject matter of study. There is a mobility issue which matters the service performance due to breakage and renewal of links of mobile nodes. Protocols performance has significance on overall performance of MANET. The aim of this study is to present the performance analysis of selected routing protocols by varying the node densities and WLAN physical characteristics. The voice and video traffic applications are configured discretely by using OLSR and DSR in scenarios. Moreover, for the performance observation the parameters are jitter, traffic received, traffic sent, end-to-end delay, traffic load, and throughput. The simulations have been carried out through OPNET 14.5 modeller tool and results has been analysed.
\end{abstract}

Keywords---- MANET, Table \& Event Driven Protocols, OPNET.

\section{INTRODUCTION}

An important wireless network environment which is a hot topic for researchers is MANET (Mobile Ad hoc Network). It is flavor of mobile wireless communication technology. The Wireless mobile Adhoc network has an important position in the field of networking. MANET depicted as it has self-organized and self-configured network layout in a situation where fixed network could not be deployed. In the MANET environment, all nodes automatically establish connectivity and develop wireless mobile network infrastructure. In this network, each node is without restraint and move independently. In this modern era of advanced technology, the MANET offers best network environment and services. But there are many issues and shortcomings in the MANET. Major issues of devices are mobility, security and scalability. . The security flaws are due to vulnerability of security protocols that degrade the performance of MANET services thus, affecting the mobility and the scalability of devices. Apparently in MANET, there are issues in routing protocols too which affects the MANET services. The connectivity flaws of Nodes degrade the MANET services. These issues occur due to routing protocols of MANET which establish the links between nodes. The goal of this study is to check the performance with the fidelity of table driven and event driven protocols by using voice \& video application in MANET. Throughput and delay parameter will be focused. This will help in understanding the trustworthiness by changing the applications and will expose how mobility is affected in the scenario of different environment.

\section{PROBLEM STATEMENT}

There are two variants of routing protocols in MANET. One is the table driven and another is the event driven protocols. Hence in this study, the table driven protocol OLSR and event driven protocol TORA or DSR performance will be analyzed by using voice application G.729 and G.711 codec and video applications like video conferencing in MANET environment through simulation. The QoS parameters throughput and delay will be focused and the scenario will be developed with different set of nodes density with dynamic mobility. In last, the results of table driven and event driven protocols will be compared by using voice and video application scenarios and will be discussed accordingly. Recommendation will also be provided for improvements.

\section{RELATED WORK}

MANET is wireless self-organized network technology which is most efficient for that geographical area where fixed network cannot be deployed. The MANET provides the vibrant infrastructure which dynamically can be deployed in a self-organized and self-configured manner [1]. Sharma et al analyzed AODV and DSR protocols by using FTP traffic in different scenarios and found the different results 
according to the nature of traffic. The results of simulation of the DSR routing protocol observed were better as compared to the AODV routing protocol in terms of special traffic parameters. Proactive protocols have good performance having the parameter of routing message overhead and end to end delay [2]. Khan et al evaluated framework of QoS and found issues between intermediate nodes during the packet delivery [3]. Mashri et al has assessed that OLSR is weak protocol as time of packet delivery is varied [4]. Singla et al compared AODV, DSDV and TORA routing protocols by CBR traffic pattern and TCP applications. The results compared by parameters average end to end delay and packet delivery ratio. The AODV is found better performing than DSDV [5]. Nawaz et al have observed that there are many architecture issues in the MANET. There are power draw backs, scalability flaws, mobility flaws and security problems in MANET [6]. Pandey et al presented the analysis of DSDV, DSR, AODV and ZRP protocols on the basis of average delay, throughput, routing overhead, and packets dropped by using ns-2 simulator [7]. Bhat et al focused on proactive, reactive and hybrid protocols (OLSR, AODV, DSR, LAR and ZRP) on the basis of average jitter, average end to end delay and packet delivery ratio by using qualnet simulator. OLSR perform better in dense network [8]. Kuppusamy et al have given the descriptive comparison of AODV, TORA and OLSR in light of end to end delay, routing overhead and packet delivery ratio metrics and the analysis shows TORA and AODV perform better than OLSR [9]. Bilandi and Verma focused on OLSR and AODV on the basis of default and varied metrics and evaluated that the performance is varied by node densities [10]. Palaniammal and Lalli has presented an overview of prominent protocols including AODV, DSR and TORA in MANET, pros and cons of these protocols has been described comparatively and it is mentioned that it is hard to decide which one is best [11]. Shrestha and Tekiner have compared selected protocols of MANET by changing network size and analysed the scalability and mobility during routing process. AODV performed better as compared to OLSR and TORA [12]. Shelja and Suresh have proposed modification of OLSR in light of table maintenance that results in improved version of OLSR as compared to existing one. It has been proposed that add one additional field message sequence number to the topology table. [13].Saravanan and Vijayakumar examined the trajectories of reactive and proactive protocols with delay and throughput metrics by using OPNET modeller 16.0 and analysis showed that reactive protocols are better for MANET [14]. Islam et al evaluated different codec of voice (G.729, G.728, G.726, G.723, G.711, GSM-HR and GSMEFR) with similar load of interactive voice. It has been mentioned in this study that G.711 is best solution for small network and GSM-EFR codec is best for large network [15]. Gandhi et al presented the evaluation of DSR, OLSR and ZRP by using ns-2 Simulator, and illustrated that DSR performed better as compared to other protocols [16]. Sharma et al presented the analysis of AODV, DSDV and ZRP by using ns-2 and illustrated that ZRP is better than
AODV and DSDV in terms of metrics which has been used like throughput [17]. Naseer et al using multimedia application analysed the TORA, AODV and OLSR with the help of opnet [18]. Gupta evaluated the mobility effect of MANET routing protocols in terms of packet delivery ratio and end to end delay by using ns-2 simulator, and observed AODV performed better [19]. Mostafavi et al has reviewed proactive and reactive routing protocols by using FTP traffic, and three parameters end to end delay, load and throughput, analysed with opnet modeller [20]. Morshed et al evaluated the DSDV and AODV protocols with QoS metrics by using ns-2 simulator and concluded AODV is efficient as compared to DSDV [21]. Kumar et al have highlighted the issues and simulator tools and metrics which have been used in Manet and presented that scalability and reliability are major issues for MANET implementation [22]. Shivahare et al have compared the proactive and reactive protocols DSDV, AODV and DSR on the basis of protocol parameters properties in descriptive form [23]. Kaur and Singh compared the OLSR, TORA and GRP on the basis of load, delay and throughput and observed that TORA perform poorly as compared to OLSR and GRP by using OPNET modeler [24].

\section{MANET PROTOCOLS}

The Mobile Adhoc network has two variants of routing protocols that perform the routing during communication.

\section{A. Table Driven Routing Protocols (TDRP)}

These routing protocols provide the routing information of each node which is available on network. Each node maintains its routing information individually. These protocols send the control message periodically for updating the routing table for every node [9]. In table driven mechanism, nodes keep track of all possible destination routes [19]. There are two prominent protocols which work under the umbrella of table driven method.

\section{a) OSLR (Optimized Link State Routing Protocol)}

OSLR works as a link state routing algorithm which is capable to flood the information of links frequently.

\section{b) DSDV (Destination sequence Distance Vector).}

On the other hand, the DSDV perform its operation like bellman ford algorithm. It is capable to compute the shortest path from single source vertex to all other vertices. In this research study, OSLR protocol is considered for performance analysis.

\section{B. Event Driven Routing Protocols (EDRP)}

These routing protocols provide the routing information when needed; therefore, these protocols are also known as on demand routing protocols. When a source node wants to communicate or send packet to destination node. The event driven routing protocols invoke the mechanism of discovery 
of route and know the destination route. The route remains active until the communication session needed it to be active [9]. The node discovers the route when needed on demand [19]. There are few prominent events driven routing protocols.

\section{a) AODV (Adhoc On demand Distance Vector)}

The AODV routing protocol algorithm offers route to the nodes when the source node request the route. It helps the nodes to easily enter and leave the network when needed. AODV Supports both unicast and multicast mechanism by performing distance vector routing.

\section{b) DSR (Dynamic Source Routing)}

DSR is the EDRP based routing protocol. It has two mechanisms. One is the route discovering and other is route maintenance. These mechanisms perform function together and allow the mobile nodes to discover the route and maintain the connectivity in mobile Ad hoc network. In this study, the DSR selected for performance analysis with OLSR protocol.

c) TORA (Temporary ordered Routing Algorithm).

\section{MANET APPLICATION}

The MANET easily adds and removes the devices and maintains connectivity. It can be deployed anywhere, where infrastructure of network is not available, inconvenient or non-existing. Initially, MANET was developed and derived for the military application to serve the purpose of network survivability and easy development. There are few mobile Adhoc network applications which have been mentioned below.

- MWB (Military War/ Battlefield)

- LL (Local Level)

- $\quad$ CL (Commercial Level)

- WMN (Wireless Mesh Network)

- HWN (Hybrid Wireless Network)

During war in battlefield, military can easily developed their mobile network by using MANET MWB platform and easily maintain their communication between troops, companies and headquarter. LL, a mobile network that can be developed for hospitals, stadiums, boats and likewise and it can maintain communication for temporary time. . CL can be helpful during disaster and emergency for relief operation for example during earthquake, flood and fire where fixed infrastructure of network is unavailable. WMN is an important application through which a separate infrastructure can be provided that can help people on their residence and business locations as alternate solutions without spectrum reuse and planning, where cellular network does not support sometimes. HWN is the solution of mobile ad hoc networking which supports the other applications for example ITS (Intelligent transport system), LE, CN and communication.

\section{A. Transmission Range}

\section{MANET METRICS}

The power constraint limits the transmission range parameter due to reuse of frequency and effects of channel [22]. Transmission range depends on the transmit power. It has been derived from mathematical formula which is given below.

$P=\left(\frac{4 \pi D}{0.12476}\right)^{2} * 10^{-11.1}$

The power value which has been used is 0.005 watt. The transmission range is required. The above formula shows that $\mathrm{D}$ is the transmission range. Hence the transmission range can be calculated by deriving the above equation.

$=P O W E R((4 * 3.14 * B 1 / 0.12476), 2) * P O W E R(10,-11.1)$

The following transmission ranges has been calculated in table 1 by using above formula:

Table 1. Transmission range

\begin{tabular}{|l|l|}
\hline Transmit Power (w) & Transmission Range(m) \\
\hline 0.000805876 & 100 \\
\hline 0.001813221 & 150 \\
\hline 0.003223504 & 200 \\
\hline 0.005036725 & 250 \\
\hline 0.007252885 & 300 \\
\hline 0.009871982 & 350 \\
\hline 0.012894017 & 500 \\
\hline 0.016318991 & \\
\hline
\end{tabular}

\section{B. Transmit Power}

The transmit power is a feature of Wireless LAN (WLAN) which has an impact on communication directly and by increasing the Transmit power, the transmission range can be increased in MANET. Moreover, it is proved through 
Mathematical formula of transmission range that increasing transmit power can directly impact transmission range. It indicates that transmission power directly impact on the performance of MANET protocols.

\section{Jitter}

The packet arrival time variation is known as jitter [9]. The delay or latency variations are also known as jitter. For the better performance, the delay or jitter should be minimum [21].

\section{Packets sent}

The data traffic sent by all mobile nodes using routing protocols in MANET during transmission or total number of packets sent by mobile nodes from source to destination.[19]

\section{Packet Received}

It is explained as data traffic received by the destination nodes during communication from source node. The received packets can be measured by subtracting lost packets and dropped packets from sent packets [19]

\section{E. Packets Dropped}

The data traffic is sent in the form of packets to the destination from source nodes but it could not reach the destination due to error condition. It is known as Packet dropped [19, 21].

\section{F. Media Access Delay}

The time required accessing a media to mobile node or mobile work station for packet transmission is known as media access delay. Initially, when packet is sent to physical layer the delay is recorded for each packet [9]. Media Access Delay may occur because of the network congestion [25].

\section{G. Network Load}

The network load corresponds to total number of bps assigned to WLAN layers for higher layers to all nodes of WLAN in the network [15]

\section{H. End to End Delay}

It is a metric or parameter that shows how much time is needed by a packet travelling from one end to another end. End to end delay having all possible delays' due to buffering in route discovering latency, propagation delay or queuing delay, are measured in seconds. The difference of sent time and receive times of packets is known as end to end delay [9, 21]. The packet end to end delay is an average time that a packet takes in transit from source to destination. End to end delay is a gauge which shows the routing protocols reliability using all constraints of the MANET [20].

\section{Throughput}

The ratio of data amount reaches from source to destination with respect of time taken by the destination to receive last packet is referred as throughput [9]. The throughput can be expressed in bps or packets per second. The phenomenon of topology change frequently effect this metric in MANET [9]. It has been analyzed in different MANET wireless environment with different metrics. The data packets successfully reached at destination, the average rate is known as throughput. Throughput is measured in bps [9].

\section{RESEARCH METHODOLOGY}

The research methodology or proposed approach which has been used in this study is the OPNET tool. In this research, performance has been analysed by evaluating the Table driven (OLSR) and event driven (DSR) MANET protocols by using voice and video traffic applications. The opnet 14.5 modeller has been used. The flow chart is mentioned below illustrates step by step activities of this study.

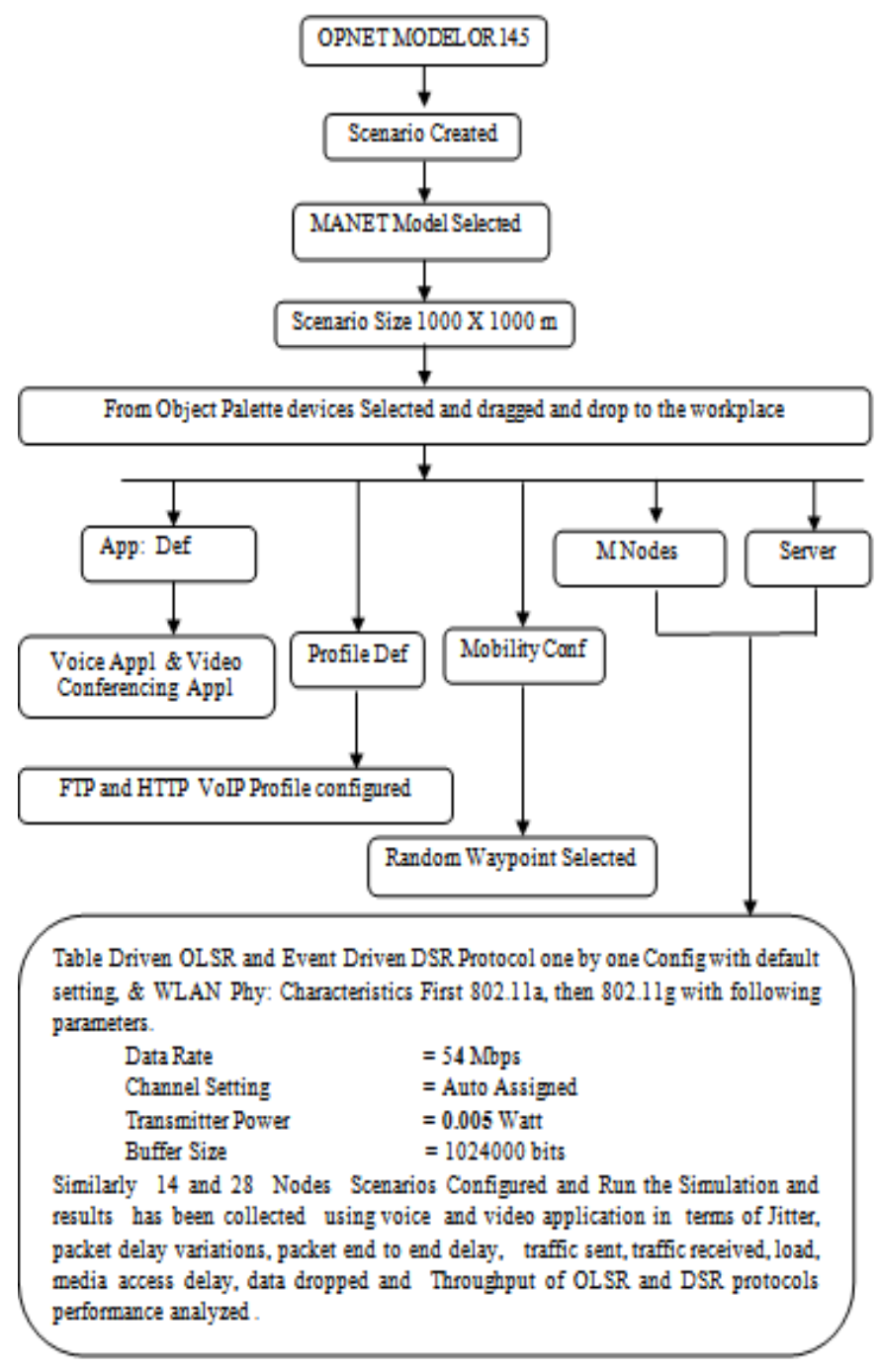

Flow Chart 1. 


\section{EXPERIMENTAL WORK AND DISCUSSION}

The experimental work is carried out by using simulation tool OPNET modeler 14.5. 2 scenarios have been developed having 14, 28 nodes. With default setting, the table driven protocol OLSR and event driven protocol DSR has been configured in both scenarios. The Wireless LAN physical characteristics standard 802.11a has been configured initially by using voice traffic. After the simulation, results were collected. Then the Wireless LAN physical characteristics standard 802.11a has been configured with video traffic. The simulation was carried out and results were collected. Similarly, the WLAN physical characteristics standard was changed as 802.11g and was configured in both scenarios by using similar attributes of traffic configuration. The simulations were carried out and the results were obtained and discussed. On other hand, the Wireless LAN attribute transmit power (w) was set to 0.005 w for both scenario node densities. The Scenarios Main Characteristics has been given below in table 2 .

Table. 2

\begin{tabular}{|l|l|}
\hline \multicolumn{1}{|c|}{ Scenarios Parameters } & Scenario Values \\
\hline Simulation tool & PNET 14.5 \\
\hline MANET Protocols & OLSR, DSR \\
\hline Campus Network Scenario Size & $1000 x 1000 \mathrm{~m}$ \\
\hline Number of Mobile Nodes & 14,28 \\
\hline Data Rate & 54 Mbps \\
\hline Application Name & Voice and Video Traffic \\
\hline Wireless LAN Phy Characteristics & 802.11 a and $802.11 \mathrm{~g}$ \\
\hline Network Protocol & IP \\
\hline Mobility model & Random Waypoint \\
\hline Scenario Simulation Time & 30 min \\
\hline
\end{tabular}

The Wireless LAN attribute Values has been given below in table 3 .

Table. 3

\begin{tabular}{|l|l|}
\hline Wireless LAN Parameters & $\begin{array}{l}\text { Wireless LAN Parameters } \\
\text { Values }\end{array}$ \\
\hline Channel Setting & Auto assigned \\
\hline Transmitter Power & 0.005 Watt \\
\hline Transmission Range & $250 \mathrm{~m}$ \\
\hline
\end{tabular}

\begin{tabular}{|l|l|}
\hline Fragmentation Threshold & 1024 bytes \\
\hline Buffer Size & 1024000 bits \\
\hline Mobile Node Speed & $10 \mathrm{~m} / \mathrm{s}$ \\
\hline
\end{tabular}

The following 2 scenarios illustrated in figure 1 and 2 are developed by using above parameters, values and attributes having 14 and 28 nodes according to given tabular values.

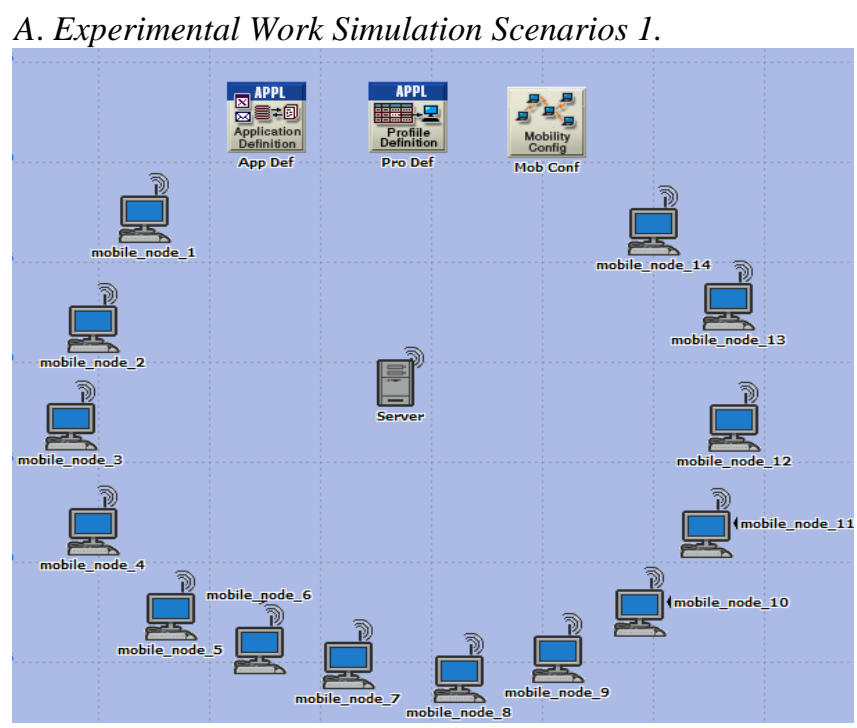

Fig. (1). Scenario 1

B. Experimental Work Simulation Scenarios 1 .

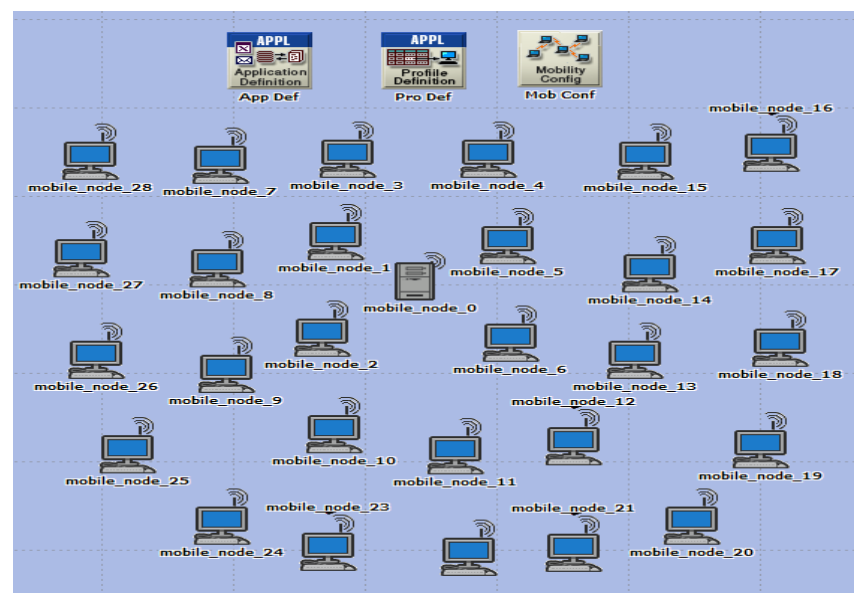

Fig. (2). Scenario 2

By using OPNET Modeler 14.5, MANET campus network has been designed with configuration of 1000x1000 meters. Two scenarios have been developed by drag and dropping the network nodes from object palette of MANET model. The network nodes include profile definition, mobility configuration, application definition server and mobile workstations dragged from object palettes and 
dropped at the workplace. Moreover, the application definition was configured with voice and video traffic separately. Primarily, the name of application definition was changed than application attributes having voice codec G.729 and video conferencing application configured with high resolution description. After that, profile definition was configured. Similarly, the name has been changed and FTP and HTTP services configured and application Voice and video conferencing were configured. The mobility configuration configured with random way point and name was also updated. The server was configured. Initially, name was changed than MANET protocols event driven (DSR) and table driven (OLSR) was configured with default setting. Server application support profile was configured and updated with the supported services. Wireless LAN bearing Physical Characteristics, features and parameters was configured. The physical characteristics of WLAN 802.11a configured with parameters as, data rate $54 \mathrm{mbps}$, auto assigned channel setting, (0.005 watt) transmitter power, 1024 fragmentation threshold and 1024000 bits buffer size was configured. The scenario 1 simulation time was set at 30 minutes. After this configuration, simulation was carried out. After completion of the simulation, the results were collected. Similarly, scenario 1 having 14 nodes was configured with same values and same parameters by changing video traffic application. The simulation was carried out. After completion of the simulation, the results were collected. After these simulations, the WLAN physical environment of the scanerio1 was changed from 802.11a to $802.11 \mathrm{~g}$ by configuring the data rate $54 \mathrm{mbps}$, auto assigned channel setting, (0.005 watt) transmitter power, 1024 fragmentation threshold and 1024000 bits buffer size. The scenario 1 simulation time was set at 30 minutes. After simulation the results were collected.

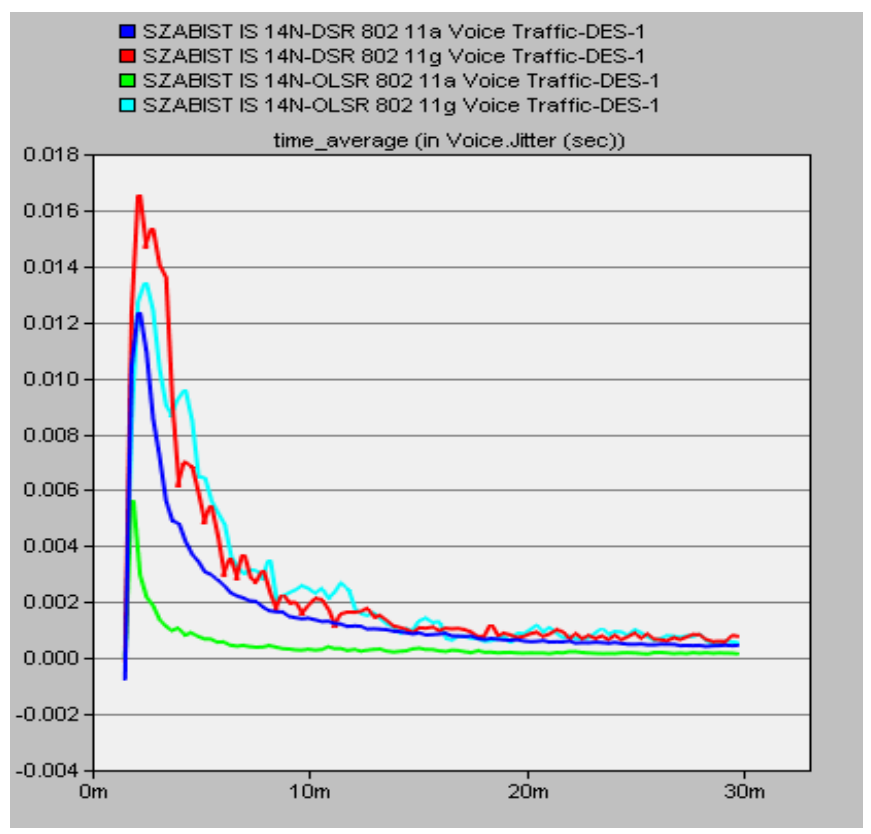

In the above Figure 3, it has been observed that in WLAN 802.11a environment for voice traffic, DSR protocol has jitter value 0.012 seconds and OLSR protocol has jitter value is 0.05 seconds. On the other hand in WLAN 802.11g environment for voice traffic, DSR has jitter value 0.017 seconds and OLSR protocol has jitter value 0.013 seconds.

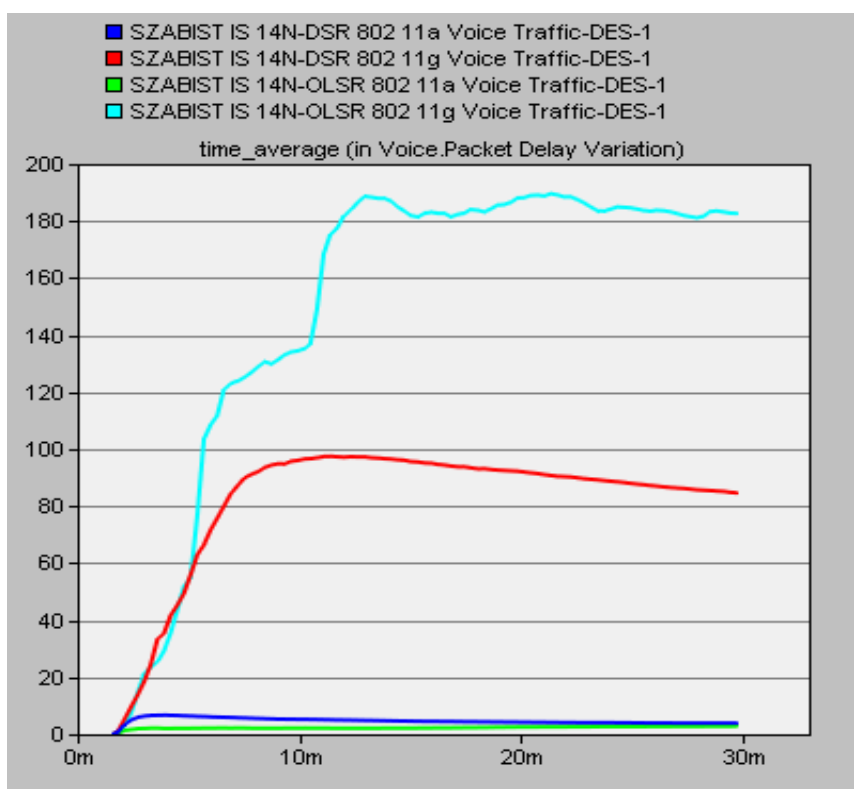

Fig. (4). Voice Traffic Packet Delay Variations

In the above Figure.4, it has been observed that in WLAN 802.11a, atmosphere for voice traffic DSR protocol has Packet Delay Variations of 5 seconds and OLSR protocol has Packet Delay Variations of 4 seconds. On the other hand, in WLAN 802.11g, atmosphere for voice traffic DSR has Packet Delay Variations of 85 seconds and OLSR protocol has Packet Delay Variations of 182 seconds. In $802.11 \mathrm{a}$, atmosphere packet delay variation of OLSR is lower than DSR and contrary in $802.11 \mathrm{~g}$ atmosphere packet delay variation of OLSR is greater than DSR.

Fig. (3). Voice Traffic Jitter 


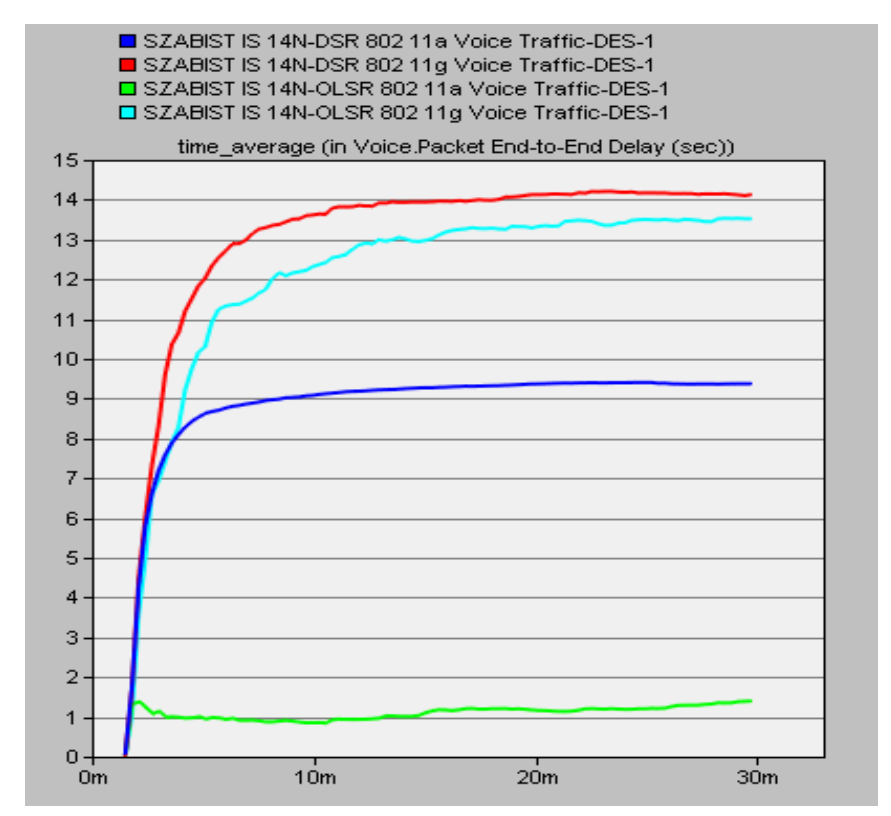

Fig. (5). Voice Traffic Packet End to End Delay

In the above Figure 5, it has been observed that in WLAN 802.11a environment, for voice traffic packet end to end delay of DSR has 9.5 seconds and OLSR protocol has 1.5 seconds packet end to end delay. On other hand, in WLAN 802.11g environment, DSR has 14 seconds packet end to end delay and OLSR has 13.5 seconds packet end to end delay. Here, DSR has greater packet end to end delay to OLSR.

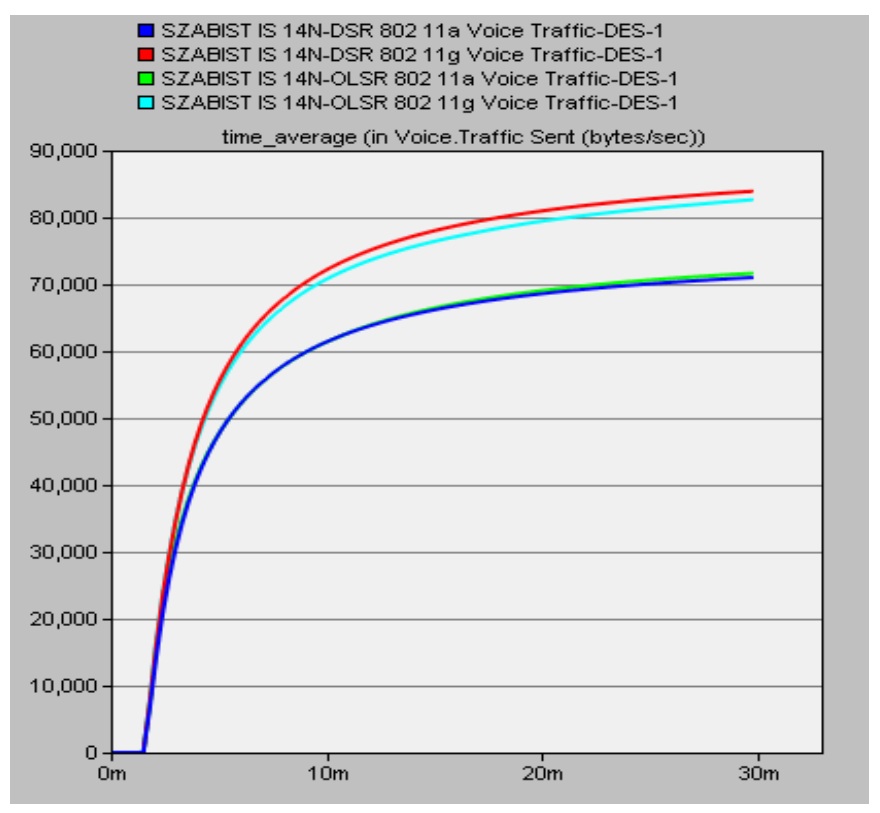

Fig. (6). Voice Traffic Sent

In the above Figure.6, it has been observed that in WLAN 802.11a atmosphere, the voice traffic sent by DSR is
70 kilo bytes/ seconds or $560 \mathrm{kbps}$ and OLSR protocol has sent 71 kilo bytes/ seconds or $568 \mathrm{kbps}$. On other hand, in WLAN $802.11 \mathrm{~g}$ atmosphere, voice traffic sent by DSR is 85 kilo bytes/seconds or $680 \mathrm{kbps}$ and OLSR protocol has sent 83 kilo bytes/seconds or $664 \mathrm{kbps}$.

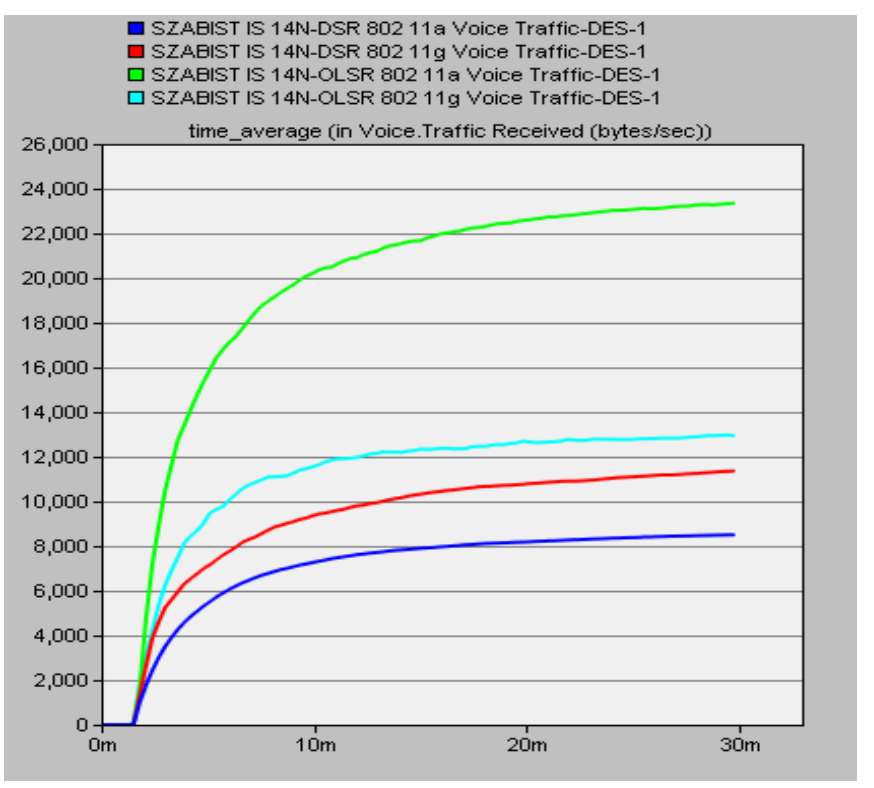

Fig. (7). Voice Traffic Received

In the above Figure 7 , it has been observed that in WLAN 802.11a atmosphere, the voice traffic received by DSR is 8.2 kilo bytes/ seconds or $65.6 \mathrm{kbps}$ and OLSR protocol has received 23.5 kilo bytes/ seconds or $188 \mathrm{kbps}$. On other hand, in WLAN 802.11g atmosphere, voice traffic received by DSR is 11.2 kilo bytes/seconds or $89.6 \mathrm{kbps}$ and OLSR protocol has received 12.5 kilo bytes/seconds or 100 kbps. 


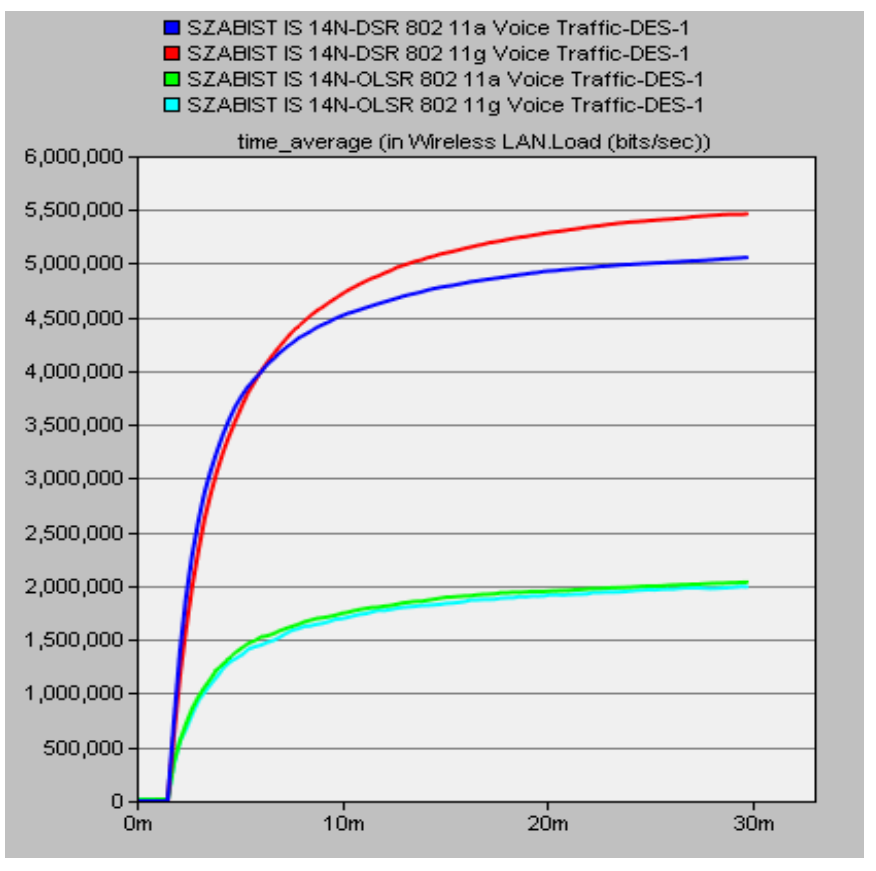

Fig. (8). Voice Traffic Load

In the above Figure 8 , it has been observed that in WLAN 802.11a environment, voice traffic network load of DSR is $5 \mathrm{mbps}$ and OLSR protocol has $2 \mathrm{mbps}$ network load. On other hand, in WLAN 802.11g environment, voice traffic network load of DSR is $5.5 \mathrm{mbps}$ and OLSR protocol has 2 mbps network load. In both WLAN physical characteristics, the DSR protocol has greater network load as compared to OLSR.

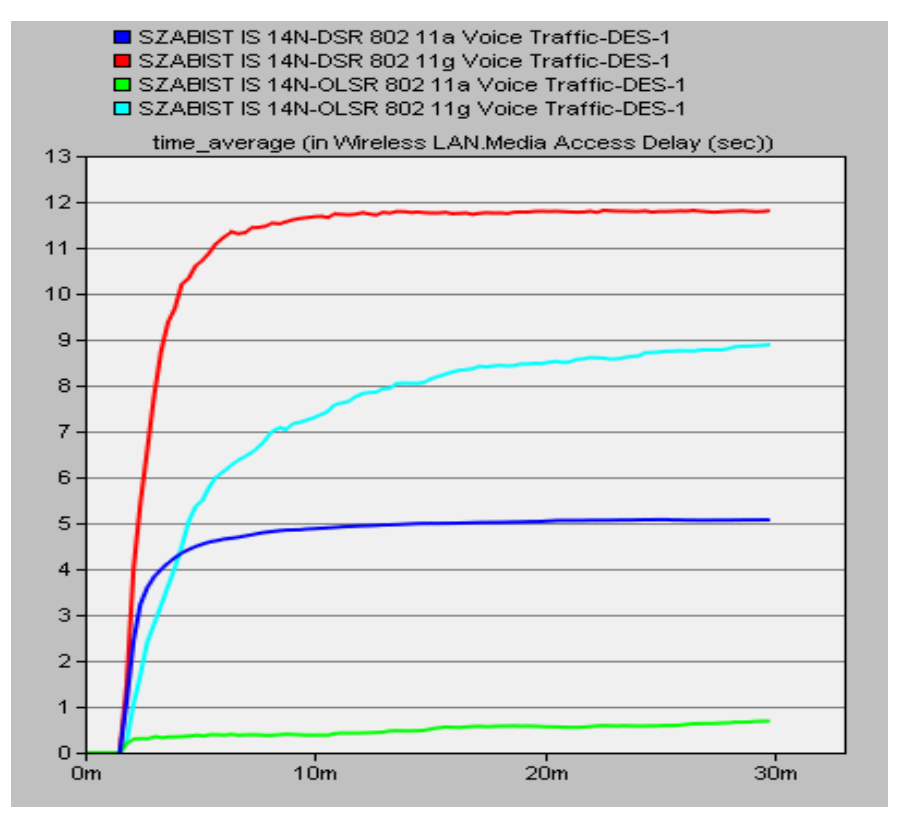

In the above Figure 9, it has been observed that in WLAN 802.11a environment, media access delay of DSR is 5 seconds and OLSR has 0.7 media access delay. On other hand in WLAN 802.11g environment, DSR has 12 seconds media access delay and OLSR has 9 seconds media access delay. It has been observed that DSR has lower media access delay in both physical characteristics of WLAN.

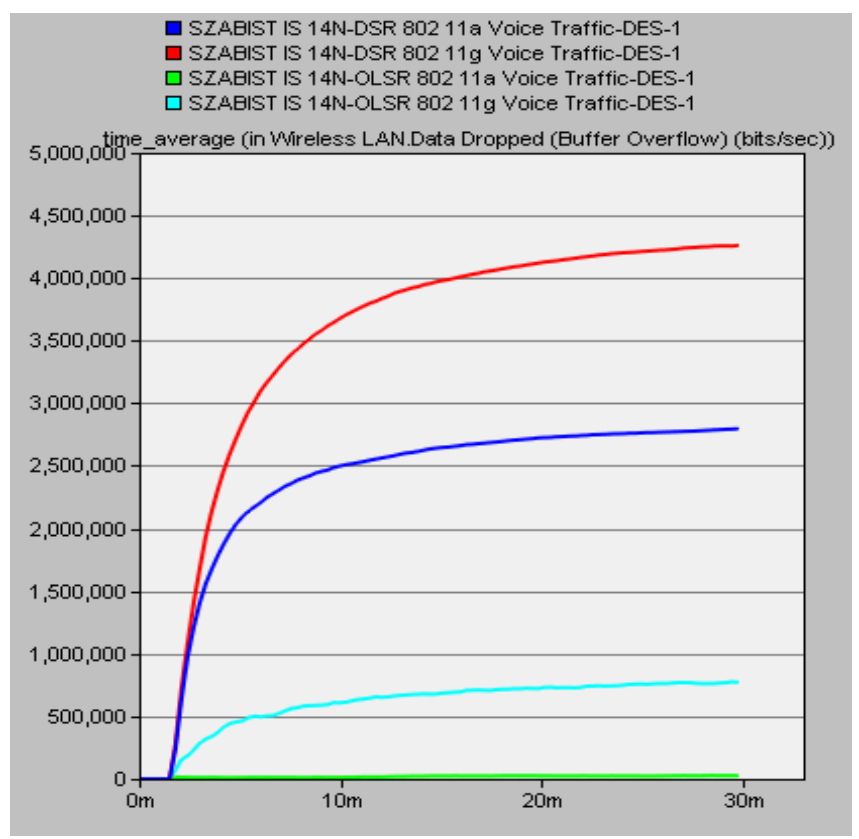

Fig. (10). Voice Traffic Data Dropped

In the above Figure 10, it has been observed that in WLAN 802.11a environment, voice traffic DSR has dropped data $2.7 \mathrm{mbps}$ and OLSR protocol dropped data $0.1 \mathrm{mbps}$. On the other hand, in WLAN 802.11g environment, for video traffic DSR has dropped data $4.25 \mathrm{mbps}$ and OLSR protocol has dropped the data $0.75 \mathrm{mbps}$. The DSR protocol has greater data dropped as compared to OLSR protocol.

Fig. (9). Voice Traffic Media Access Delay 


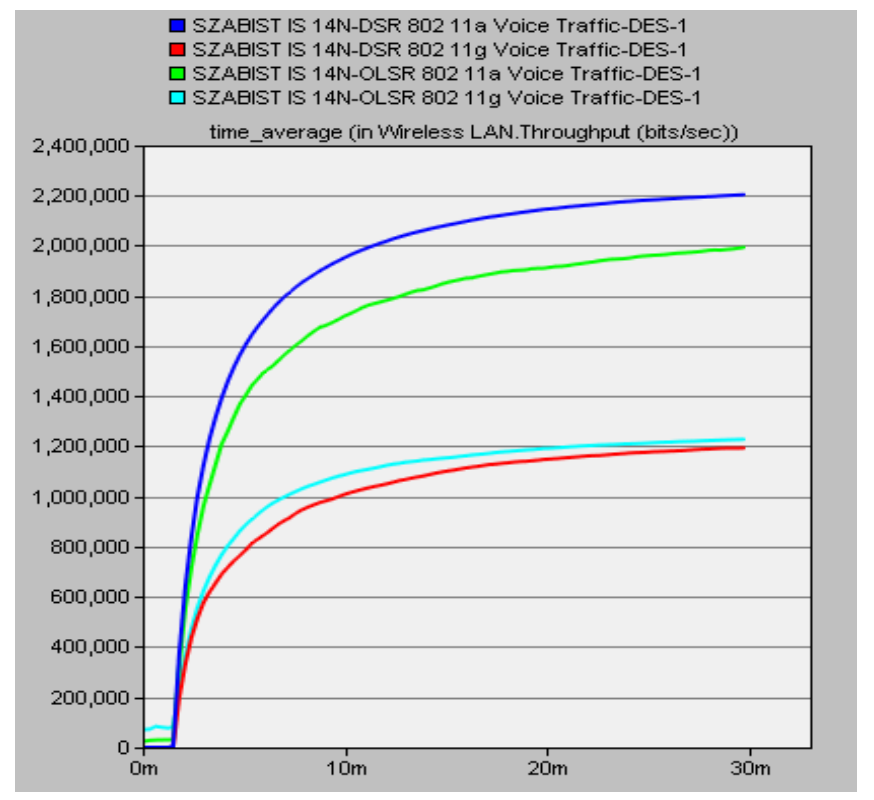

Fig. (11). Voice Traffic Throughput

In the above Figure 11, it has been observed that in WLAN 802.11a environment, for voice traffic DSR has 2.2 mbps throughput and OLSR protocol have $2 \mathrm{mbps}$ throughput. On other hand, in WLAN 802.11g environment for voice traffic DSR has $1.2 \mathrm{mbps}$ throughput and OLSR protocol has $1.22 \mathrm{mbps}$.

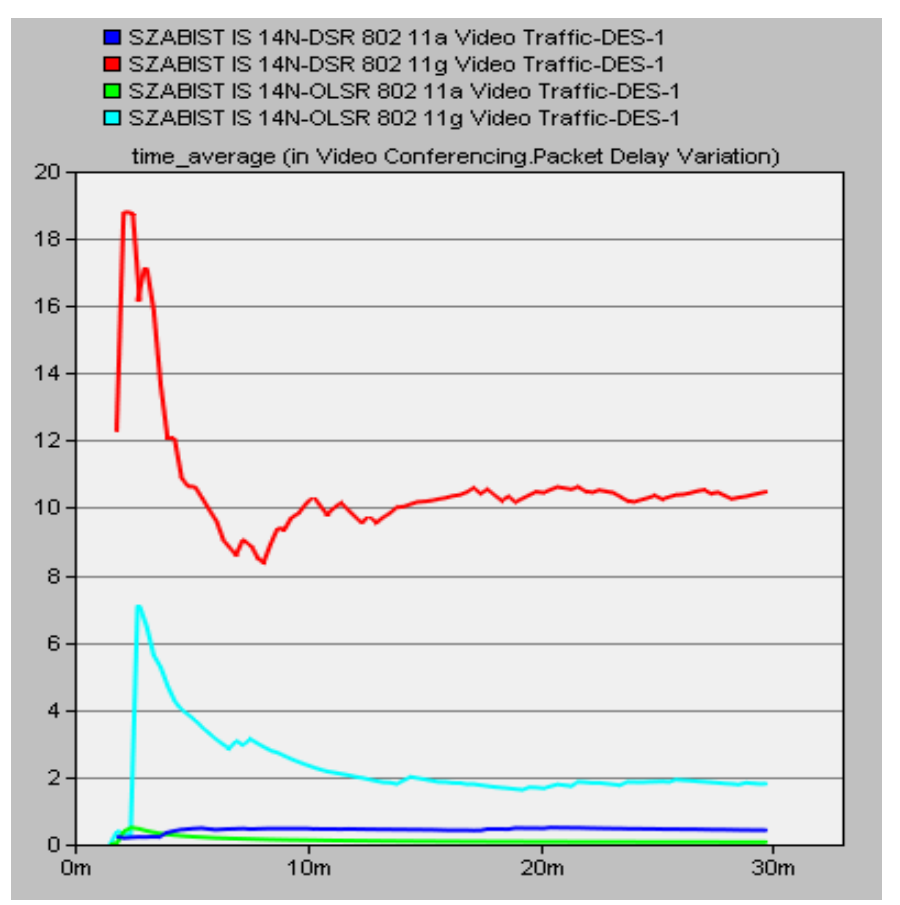

In the above Figure 12, it has been observed that in WLAN 802.11a atmosphere, for video traffic DSR protocol has Packet Delay Variations of 0.4 seconds and OLSR protocol has Packet Delay Variations of 0.1 seconds. On the other hand, in WLAN 802.11g atmosphere for video traffic DSR has Packet Delay Variations 19 seconds and OLSR protocol has Packet Delay Variations of 7 seconds. In video traffic, a packet delay variations of OLSR is lower than DSR in both WLAN physical characteristics.

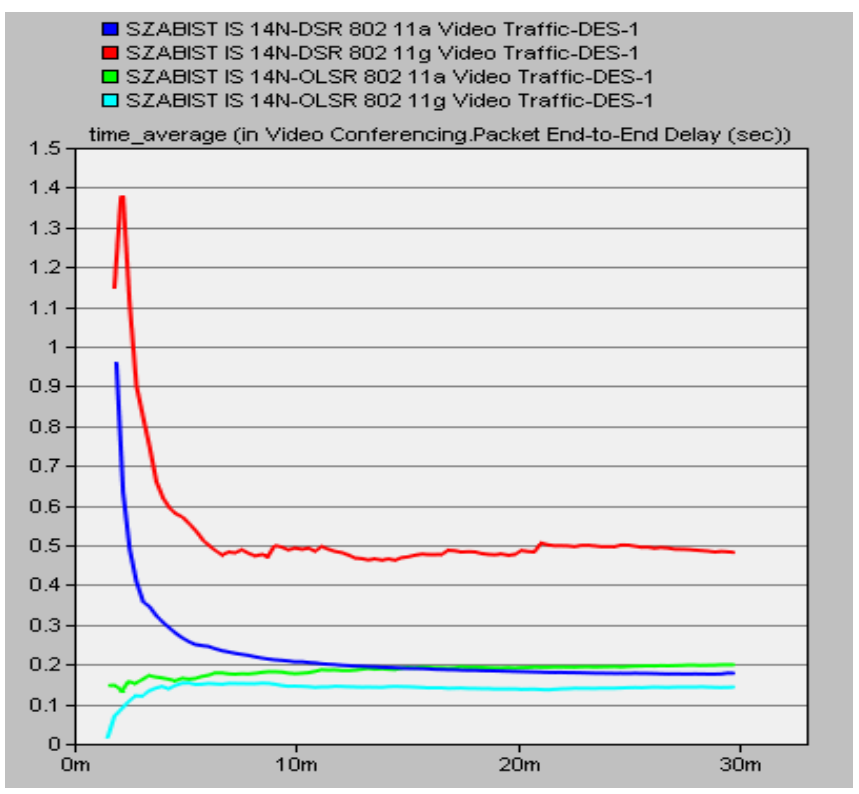

Fig. (13). Video Traffic Packet End to End Delay

In the above Figure 13, it has been observed that in WLAN 802.11a environment, for video traffic packet DSR has 0.96 seconds end to end delay and OLSR protocol has 0.2 seconds of packet end to end delay. On other hand, in WLAN 802.11g environment, DSR has 1.37 seconds packet end to end delay and OLSR has 0.15 seconds packet end to end delay. The DSR has greater packet end to end delay as compared to OLSR.

Fig. (12). Video Traffic Packet Delay Variations 


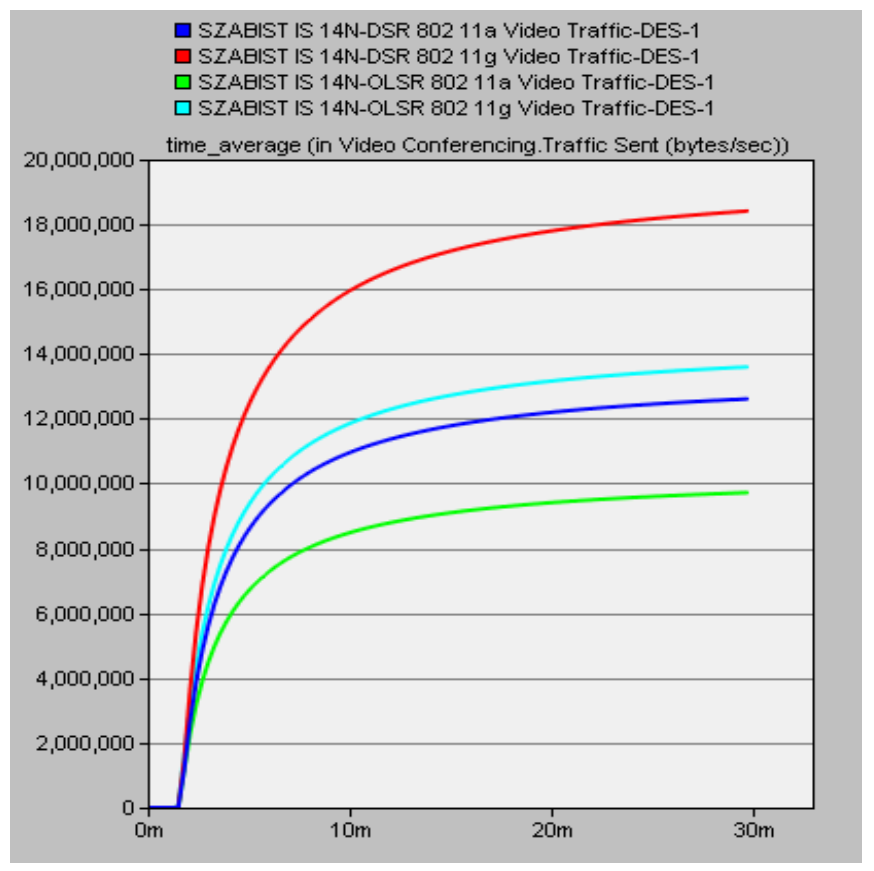

Fig. (14). Video Traffic Sent

In the above Figure 14, it has been observed that in WLAN 802.11a atmosphere, the video traffic sent by DSR is 12.3 megabytes/ seconds or $98.4 \mathrm{mbps}$ and OLSR protocol has sent 9.4 megabytes/ seconds or $75.2 \mathrm{mbps}$. On other hand, in WLAN 802.11g atmosphere, video traffic sent by DSR is 18.2 megabytes/seconds or $145.6 \mathrm{mbps}$ and OLSR protocol has sent 12.8 megabytes/seconds or $102.4 \mathrm{mbps}$.

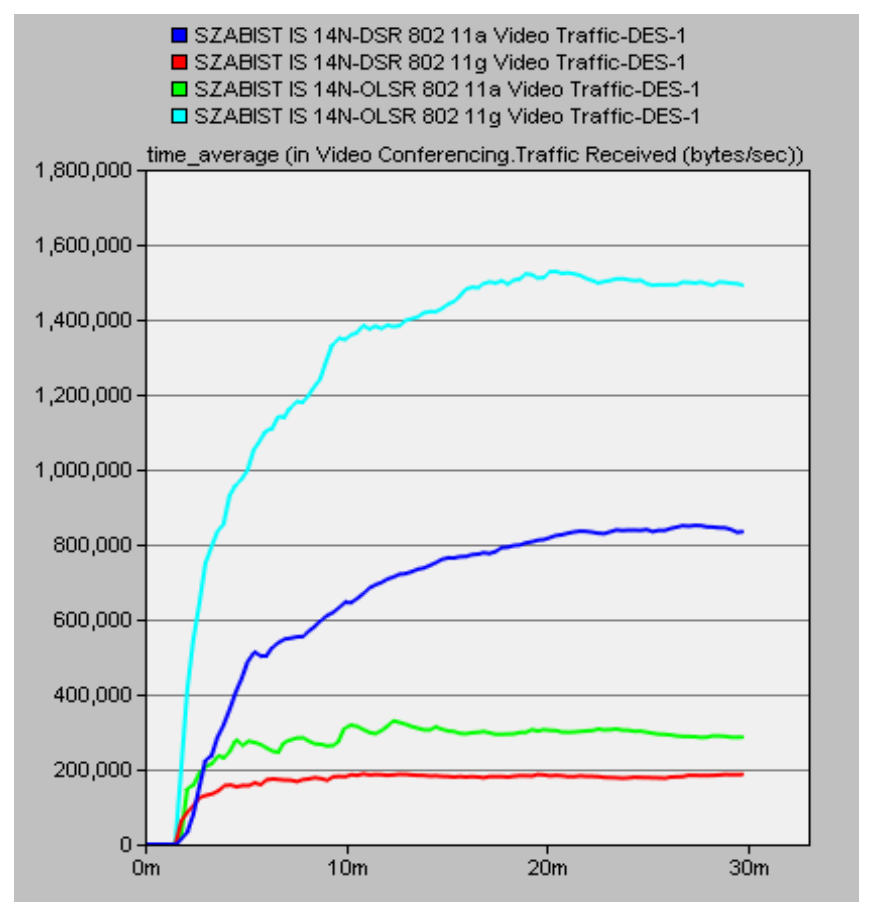

Fig. (15). Video Traffic Received
In the above Figure 15, it has been observed that in WLAN 802.11a atmosphere, the video traffic received by DSR is 800 kilo bytes/ seconds or $8.4 \mathrm{mbps}$, and OLSR protocol has received 300 kilo bytes/ seconds or $2.4 \mathrm{mbps}$. On other hand, in WLAN 802.11g atmosphere, video traffic received by DSR is 200 kilo bytes/seconds or $1.6 \mathrm{mbps}$ and OLSR protocol has received 1500 kilo bytes/seconds or 12 mbps.

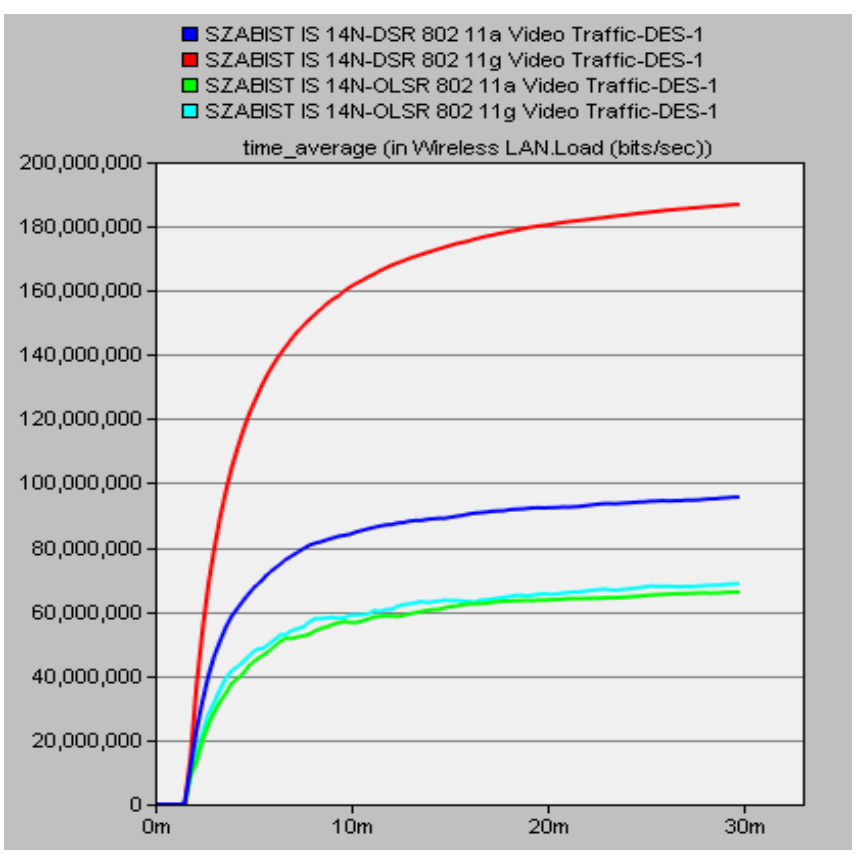

Fig. (16). Video Traffic Load

In the above Figure 16, it has been observed that in WLAN 802.11a environment for video traffic, the network load of DSR is $96 \mathrm{mbps}$ and OLSR protocol has $65 \mathrm{mbps}$ network load. On other hand, in WLAN 802.11g environment for voice traffic, network load of DSR is 186 mbps and OLSR protocol has $70 \mathrm{mbps}$ network load. The DSR protocol has greater network load as compared to OLSR. 


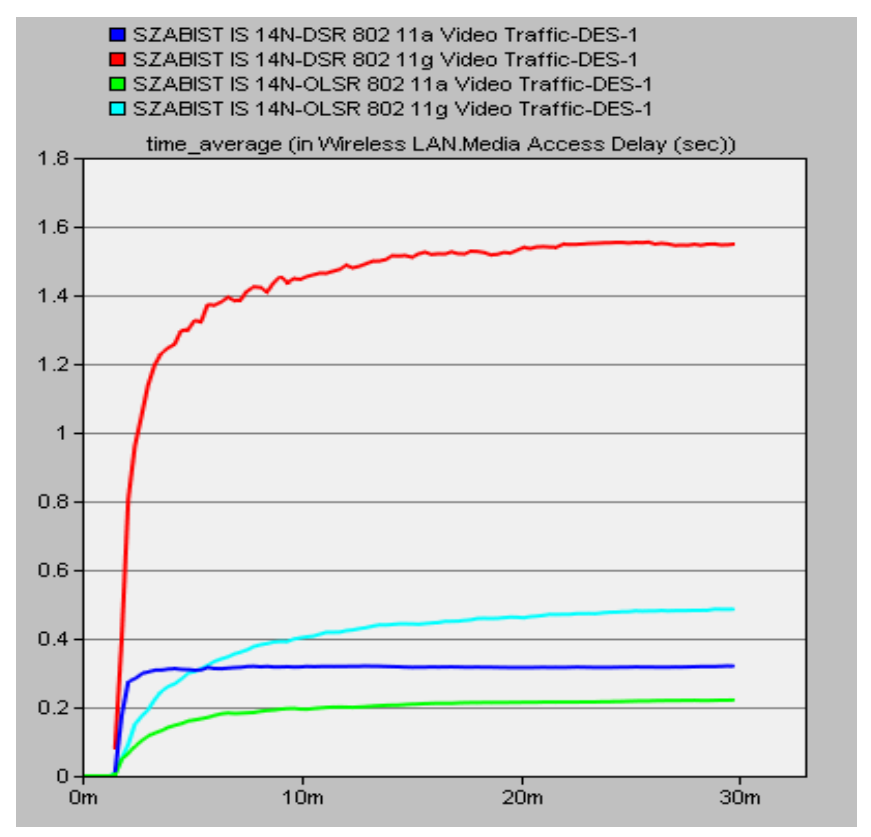

Fig. (17). Video Traffic Media Access Delay

In the above Figure 17, it has been observed that in WLAN 802.11a environment for video traffic, media access delay of DSR is 0.3 seconds and OLSR has 0.21 seconds of media access delay. On other hand in WLAN 802.11g environment for video traffic, DSR protocol has 1.55 seconds of media access delay and OLSR has 0.5 seconds of media access delay. It has been observed that DSR has greater media access delay in both physical characteristics of WLAN.

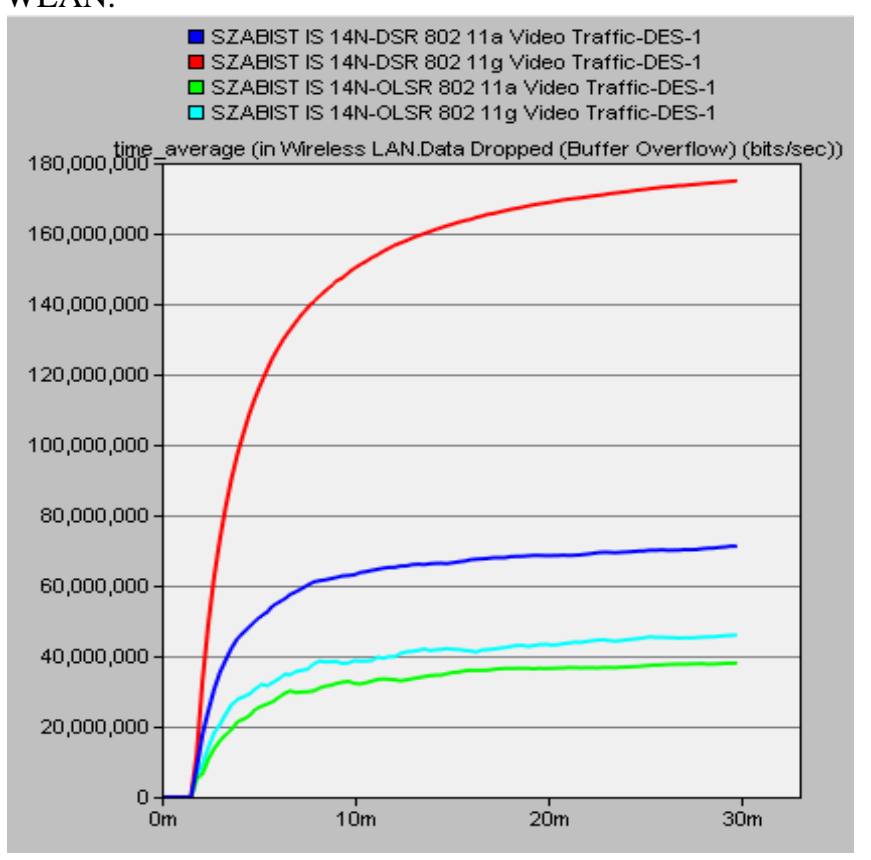

Fig. (18). Video Traffic Data Dropped

In the above Figure 18, it has been observed that in WLAN 802.11a environment for video traffic, DSR has dropped 70 mbps data and OLSR protocol dropped data 40 mbps. On the other hand in WLAN 802.11g environment for video traffic, DSR has dropped data $178 \mathrm{mbps}$ and OLSR protocol has dropped the data $47 \mathrm{mbps}$. The DSR protocol has greater data dropped as compared to OLSR protocol in both WLAN environments.

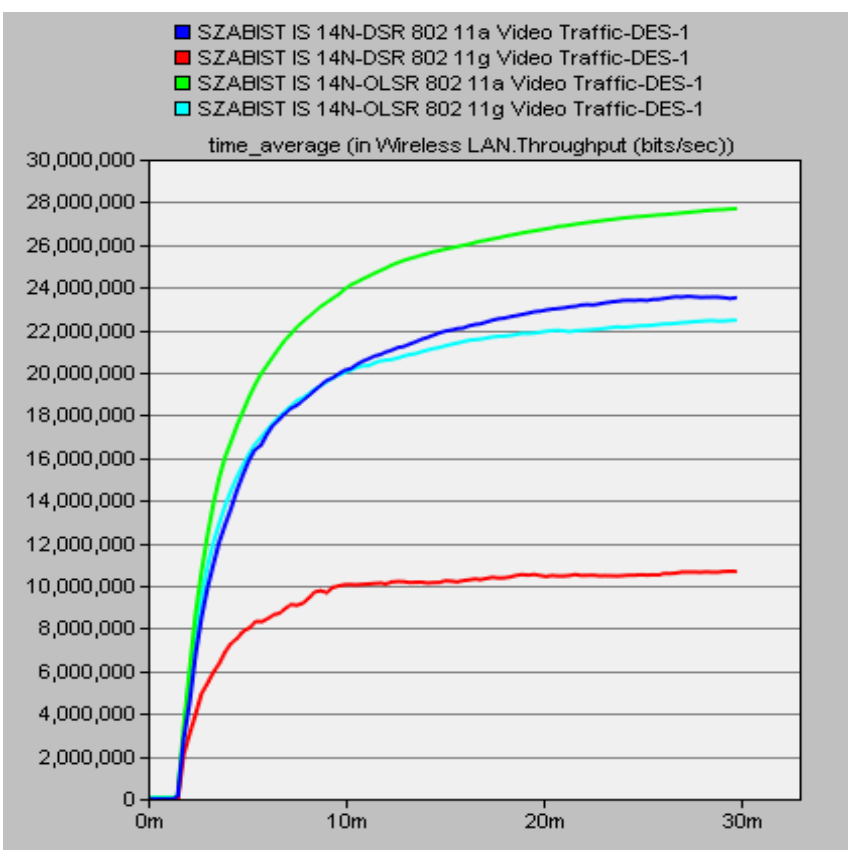

Fig. (19). Video Traffic Throughput

In the above Figure 19, it has been observed that in WLAN 802.11a environment for video traffic, DSR has 23.8 mbps throughput and OLSR protocol have $28 \mathrm{mbps}$ throughput. On other hand in WLAN 802.11g environment for video traffic, DSR has $10.8 \mathrm{mbps}$ throughput and OLSR protocol has $22.3 \mathrm{mbps}$. In performance comparison, OLSR protocol has greater throughput than DSR. 


\section{RESULTS ANALYSIS OF EXPERIMENTAL WORK OF SCENARIO 1 AND SCENARIO 2}

Table. 4

\begin{tabular}{|c|c|c|c|c|}
\hline \multicolumn{5}{|c|}{ SCENARIO 1 VOICE TRAFFIC } \\
\hline Data Traffic Type & \multicolumn{2}{|c|}{ Voice Traffic } & \multicolumn{2}{|c|}{ Voice Traffic } \\
\hline $\begin{array}{ll}\text { WLAN } & \text { Phy } \\
\text { Characteristics } & \end{array}$ & \multicolumn{2}{|c|}{ WLAN 802.11a } & \multicolumn{2}{|c|}{ WLAN $802.11 \mathrm{~g}$} \\
\hline Protocol & DSR & OLSR & DSR & OLSR \\
\hline Node Density & \multicolumn{4}{|l|}{14} \\
\hline Jitter & $\begin{array}{l}0.012 \\
\text { sec }\end{array}$ & $\begin{array}{l}0.05 \\
\sec \end{array}$ & $\begin{array}{l}0.017 \\
\text { sec }\end{array}$ & $\begin{array}{l}0.013 \\
\text { sec }\end{array}$ \\
\hline Packet Delay Variations & $\begin{array}{l}5 \\
\text { sec }\end{array}$ & $\begin{array}{l}4 \\
\text { sec }\end{array}$ & $\begin{array}{l}85 \\
\text { sec }\end{array}$ & $\begin{array}{l}182 \\
\mathrm{sec}\end{array}$ \\
\hline $\begin{array}{l}\text { Packet End to End } \\
\text { Delay }\end{array}$ & $\begin{array}{l}9.5 \\
\mathrm{sec}\end{array}$ & $\begin{array}{l}1.5 \\
\mathrm{sec}\end{array}$ & $\begin{array}{l}14 \\
\text { sec }\end{array}$ & $\begin{array}{l}13.5 \\
\mathrm{sec}\end{array}$ \\
\hline Voice Traffic Sent & $\begin{array}{l}560 \\
\text { Kbps }\end{array}$ & $\begin{array}{l}568 \\
\text { kbps }\end{array}$ & $\begin{array}{l}680 \\
\text { kbps }\end{array}$ & $\begin{array}{l}664 \\
\text { kbps }\end{array}$ \\
\hline Voice Traffic Received & $\begin{array}{l}65 \\
\text { kbps }\end{array}$ & $\begin{array}{l}184 \\
\text { kbps }\end{array}$ & $\begin{array}{l}88 \\
\text { kbps }\end{array}$ & $\begin{array}{l}104 \\
\text { kbps }\end{array}$ \\
\hline WLAN Traffic Load & $\begin{array}{l}5 \\
\mathrm{mbps}\end{array}$ & $\begin{array}{l}2 \\
\text { mbps }\end{array}$ & $\begin{array}{l}5.5 \\
\mathrm{mbps}\end{array}$ & $\begin{array}{l}2 \\
\text { mbps }\end{array}$ \\
\hline $\begin{array}{l}\text { WLAN Media Access } \\
\text { Delay }\end{array}$ & $5 \mathrm{sec}$ & $0.7 \mathrm{sec}$ & $12 \mathrm{sec}$ & $9 \mathrm{sec}$ \\
\hline WLAN Data Dropped & $\begin{array}{l}2.7 \\
\text { mbps }\end{array}$ & $\begin{array}{l}0.1 \\
\text { mbps }\end{array}$ & $\begin{array}{l}4.25 \\
\mathrm{mbps}\end{array}$ & $\begin{array}{l}0.75 \\
\mathrm{mbps}\end{array}$ \\
\hline WLAN Throughput & $\begin{array}{l}2.2 \\
\text { mbps }\end{array}$ & $\begin{array}{l}2 \\
\text { mbps }\end{array}$ & $\begin{array}{l}1.2 \\
\text { mbps }\end{array}$ & $\begin{array}{l}1.22 \\
\text { mbps }\end{array}$ \\
\hline
\end{tabular}

Table. 5

\begin{tabular}{|c|c|c|c|c|}
\hline \multicolumn{5}{|c|}{ SCENARIO 1 VIDEO TRAFFIC } \\
\hline Data Traffic Type & \multicolumn{2}{|c|}{ Video Traffic } & \multicolumn{2}{|c|}{ Video Traffic } \\
\hline $\begin{array}{ll}\text { WLAN } & \text { Phy } \\
\text { Characteristics } & \end{array}$ & \multicolumn{2}{|c|}{ WLAN 802.11a } & \multicolumn{2}{|c|}{ WLAN $802.11 \mathrm{~g}$} \\
\hline Protocol & DSR & OLSR & DSR & OLSR \\
\hline Node Density & \multicolumn{4}{|l|}{14} \\
\hline Packet Delay Variations & $\begin{array}{l}0.4 \\
\mathrm{sec}\end{array}$ & $\begin{array}{l}0.1 \\
\text { sec }\end{array}$ & $\begin{array}{l}19 \\
\text { sec }\end{array}$ & $\begin{array}{l}7 \\
\text { sec }\end{array}$ \\
\hline $\begin{array}{l}\text { Packet End to End } \\
\text { Delay }\end{array}$ & $\begin{array}{l}0.96 \\
\mathrm{sec}\end{array}$ & $\begin{array}{l}0.2 \\
\sec \end{array}$ & $\begin{array}{l}1.37 \\
\mathrm{sec}\end{array}$ & $\begin{array}{l}0.15 \\
\text { sec }\end{array}$ \\
\hline Video Traffic Sent & $\begin{array}{l}12.3 \\
\mathrm{mbps}\end{array}$ & $\begin{array}{l}9.4 \\
\text { mbps }\end{array}$ & $\begin{array}{l}18.2 \\
\mathrm{mbps}\end{array}$ & $\begin{array}{l}12.8 \\
\text { mbps }\end{array}$ \\
\hline Video Traffic Received & $\begin{array}{l}0.82 \\
\text { mbps }\end{array}$ & $\begin{array}{l}0.3 \\
\mathrm{mbps}\end{array}$ & $\begin{array}{l}0.2 \\
\mathrm{mbps}\end{array}$ & $\begin{array}{l}1.5 \\
\mathrm{mbps}\end{array}$ \\
\hline WLAN Traffic Load & $\begin{array}{l}96 \\
\text { mbps }\end{array}$ & $\begin{array}{l}65 \\
\mathrm{mps}\end{array}$ & $\begin{array}{l}186 \\
\mathrm{mbps}\end{array}$ & $\begin{array}{l}70 \\
\text { mbps }\end{array}$ \\
\hline $\begin{array}{l}\text { WLAN Media Access } \\
\text { Delay }\end{array}$ & $\begin{array}{l}0.3 \\
\mathrm{sec}\end{array}$ & $\begin{array}{l}0.21 \\
\sec \end{array}$ & $\begin{array}{l}1.55 \\
\mathrm{sec}\end{array}$ & $\begin{array}{l}0.5 \\
\mathrm{sec}\end{array}$ \\
\hline WLAN Data Dropped & $\begin{array}{l}70 \\
\text { mbps }\end{array}$ & $\begin{array}{l}40 \\
\text { mbps }\end{array}$ & $\begin{array}{l}178 \\
\mathrm{mbps}\end{array}$ & $\begin{array}{l}47 \\
\mathrm{mbps}\end{array}$ \\
\hline WLAN Throughput & $\begin{array}{l}23.8 \\
\mathrm{mbps}\end{array}$ & $\begin{array}{l}28 \\
\text { mbps }\end{array}$ & $\begin{array}{l}10.8 \\
\mathrm{mbps}\end{array}$ & $\begin{array}{l}22.3 \\
\text { mbps }\end{array}$ \\
\hline
\end{tabular}


Table. 6

\begin{tabular}{|c|c|c|c|c|}
\hline Data Traffic Type & \multicolumn{2}{|c|}{ Voice Traffic } & \multicolumn{2}{|c|}{ Voice Traffic } \\
\hline $\begin{array}{ll}\text { WLAN } & \text { Phy } \\
\text { Characteristics } & \end{array}$ & \multicolumn{2}{|c|}{ WLAN 802.11a } & \multicolumn{2}{|c|}{ WLAN $802.11 \mathrm{~g}$} \\
\hline Protocol & DSR & OLSR & DSR & OLSR \\
\hline Node Density & 28 & & & \\
\hline Jitter & $\begin{array}{l}0.019 \\
\sec \end{array}$ & $\begin{array}{l}0.007 \\
\text { sec }\end{array}$ & $\begin{array}{l}0.019 \\
\text { sec }\end{array}$ & $\begin{array}{l}0.028 \\
\text { sec }\end{array}$ \\
\hline $\begin{array}{ll}\text { Packet } & \text { Delay } \\
\text { Variations } & \end{array}$ & $\begin{array}{l}120 \\
\sec \end{array}$ & $\begin{array}{l}100 \\
\sec \end{array}$ & $\begin{array}{l}280 \\
\sec \end{array}$ & $\begin{array}{l}440 \\
\sec \end{array}$ \\
\hline $\begin{array}{l}\text { Packet End to End } \\
\text { Delay }\end{array}$ & $\begin{array}{l}22 \\
\sec \end{array}$ & $\begin{array}{l}8 \\
\sec \end{array}$ & $\begin{array}{l}31 \\
\mathrm{sec}\end{array}$ & $\begin{array}{l}34.5 \\
\sec \end{array}$ \\
\hline Voice Traffic Sent & $\begin{array}{l}424 \\
\text { kbps }\end{array}$ & $\begin{array}{l}440 \\
\text { kbps }\end{array}$ & $\begin{array}{l}432 \\
\text { kbps }\end{array}$ & $\begin{array}{l}440 \\
\text { kbps }\end{array}$ \\
\hline $\begin{array}{ll}\text { Voice } & \text { Traffic } \\
\text { Received } & \end{array}$ & $\begin{array}{l}63.2 \\
\text { kbps }\end{array}$ & $\begin{array}{l}140 \\
\text { kbps }\end{array}$ & $\begin{array}{l}64 \\
\text { kbps }\end{array}$ & $\begin{array}{l}65.6 \\
\text { kbps }\end{array}$ \\
\hline WLAN Traffic Load & $\begin{array}{l}5.2 \\
\text { mbps }\end{array}$ & $\begin{array}{l}2.2 \\
\text { mbps }\end{array}$ & $\begin{array}{l}4.8 \\
\text { mbps }\end{array}$ & $\begin{array}{l}1.9 \\
\text { mbps }\end{array}$ \\
\hline $\begin{array}{l}\text { WLAN Media Access } \\
\text { Delay }\end{array}$ & $\begin{array}{l}14 \\
\sec \end{array}$ & $\begin{array}{l}4 \\
\text { sec }\end{array}$ & $\begin{array}{l}23.3 \\
\sec \end{array}$ & $\begin{array}{l}20.1 \\
\sec \end{array}$ \\
\hline WLAN Data Dropped & $\begin{array}{l}3.3 \\
\text { mbps }\end{array}$ & $\begin{array}{l}0.7 \\
\text { mbps }\end{array}$ & $\begin{array}{l}3.7 \\
\text { mbps }\end{array}$ & $\begin{array}{l}0.2 \\
\mathrm{mbps}\end{array}$ \\
\hline WLAN Throughput & $\begin{array}{l}17 \\
\text { mbps }\end{array}$ & $\begin{array}{l}21 \\
\text { mbps }\end{array}$ & $\begin{array}{l}11.2 \\
\text { mbps }\end{array}$ & $\begin{array}{l}12 \\
\text { mbps }\end{array}$ \\
\hline
\end{tabular}

Table. 7

\begin{tabular}{|l|l|l|}
\hline \multicolumn{2}{|l|}{ SCENARIO 2 VOICE TRAFFIC } \\
\hline Data Traffic Type & Video Traffic & Video Traffic \\
\hline $\begin{array}{l}\text { WLAN Phy } \\
\text { Characteristics }\end{array}$ & WLAN 802.11a & WLAN 802.11g \\
\hline
\end{tabular}

\begin{tabular}{|c|c|c|c|c|}
\hline Protocol & DSR & OLSR & DSR & OLSR \\
\hline Node Density & \multicolumn{4}{|l|}{28} \\
\hline $\begin{array}{l}\text { Packet } \quad \text { Delay } \\
\text { Variations }\end{array}$ & $\begin{array}{l}88 \\
\text { sec }\end{array}$ & $\begin{array}{l}1 \\
\sec \end{array}$ & $\begin{array}{l}72 \\
\sec \end{array}$ & $\begin{array}{l}3 \\
\sec \end{array}$ \\
\hline $\begin{array}{l}\text { Packet End to End } \\
\text { Delay }\end{array}$ & $\begin{array}{l}13.2 \\
\sec \end{array}$ & $\begin{array}{l}0.2 \\
\sec \end{array}$ & $\begin{array}{l}7.8 \\
\sec \end{array}$ & $\begin{array}{l}0.9 \\
\sec \end{array}$ \\
\hline Video Traffic Sent & $\begin{array}{l}29 \\
\text { mbps }\end{array}$ & $\begin{array}{l}21 \\
\text { mbps }\end{array}$ & $\begin{array}{l}36 \\
\mathrm{mbps}\end{array}$ & $\begin{array}{l}38 \\
\text { mbps }\end{array}$ \\
\hline $\begin{array}{ll}\text { Video } & \text { Traffic } \\
\text { Received } & \end{array}$ & $\begin{array}{l}80 \\
\text { kbps }\end{array}$ & $\begin{array}{l}280 \\
\text { kbps }\end{array}$ & $\begin{array}{l}139 \\
\text { kbps }\end{array}$ & $\begin{array}{l}40 \\
\text { kbps }\end{array}$ \\
\hline WLAN Traffic Load & $\begin{array}{l}270 \\
\text { mbps }\end{array}$ & $\begin{array}{l}95 \\
\text { mbps }\end{array}$ & $\begin{array}{l}370 \\
\mathrm{mbps}\end{array}$ & $\begin{array}{l}230 \\
\text { mbps }\end{array}$ \\
\hline $\begin{array}{l}\text { WLAN Media Access } \\
\text { Delay }\end{array}$ & $\begin{array}{l}2.5 \\
\mathrm{sec}\end{array}$ & $\begin{array}{l}0.7 \\
\sec \end{array}$ & $\begin{array}{l}2.43 \\
\sec \end{array}$ & $\begin{array}{l}1.35 \\
\mathrm{sec}\end{array}$ \\
\hline WLAN Data Dropped & $\begin{array}{l}255 \\
\mathrm{mbps}\end{array}$ & $\begin{array}{l}70 \\
\mathrm{mbps}\end{array}$ & $\begin{array}{l}355 \\
\mathrm{mbps}\end{array}$ & $\begin{array}{l}215 \\
\text { mbps }\end{array}$ \\
\hline WLAN Throughput & $\begin{array}{l}10.5 \\
\mathrm{mbps}\end{array}$ & $\begin{array}{l}23 \\
\text { mbps }\end{array}$ & $\begin{array}{l}14 \\
\mathrm{mbps}\end{array}$ & $\begin{array}{l}18 \\
\text { mbps }\end{array}$ \\
\hline
\end{tabular}

\section{CONCLUSION}

This research paper provides comprehensive performance analysis of table driven (OLSR) and event driven (DSR) protocol of Mobile Adhoc Network using voice and video application services and different node densities with different WLAN physical characteristics such as; WLAN 802.11a and WLAN 802.11g. It evident in table $4,5,6$ and 7 that when the voice application is used in MANET plate form, the OLSR and DSR performance varies in WLAN 802.11a and 802.11g environment. The analysis shows that the voice traffic received and throughput in OLSR is greater than DSR.

Moreover, the traffic load, media access delay and data dropped are grater in DSR as compared to OLSR. From this observation, it can be concluded that OLSR has better performance than DSR but it is table driven. However, there were few variations observed in the behaviour of protocol when the node density was changed from 14 nodes to 28 nodes. When the video applications was used with same setting in MANET plate form; the OLSR and DSR 
performance varied as compared to voice application. These protocols perform better in high load. The throughput is greater in video traffic as compared to voice traffic. Similarly, OLSR performed better in terms of throughput in both WLAN 802.11a and 802.11g environment. WLAN $802.11 \mathrm{~g}$ proved to be a better platform for table driven and event driven protocols in terms of providing better services as compared to 802.11a. The table driven and event driven routing protocol metrics performance varied. It depends on the application type, WLAN physical characteristics and number of nodes. In this regards, these protocols behavior were found to be changed. The transmission power and transmission range also have impact on these protocol performance.

\section{FUTURE WORK}

In MANET, there are architecture issues, transmit power issues, mobility issues, scalability issues and security issues. The routing protocol algorithms could be improved for the better performance. These are vast areas in which research can be carried out and Mobile Adhoc Network can be improved.

\section{ACKNOWLEDGEMENT}

First of all, I would like to thanks Almighty Allah, who enables me, bestow knowledge, ability, understanding and stability upon me to complete this study.

I would further like to thank Dr. Hasnain Mansoor Ali for his support, direction, collaboration, synchronization and valuable implication during this study.

\section{REFERENCES}

[1] P. Dadral, R. Vohra and R. S. Sawhney "Metrics Improvement of MANET Using Reactive Protocols Approach" In Proceedings of International Conference on Parallel, Distributed and Grid Computing, 2012.

[2] M. L. Sharma N. F. Rizvi, N. Sharma, A. Malhan and S. Sharma "Performance Evaluation of MANET Routing Protocols under CBR and FTP traflic classes", International Journal of Computer Technology and Applications, vol. 2, no. 3, pp: 392-400.

[3] J. khan, S. I. Hyder and K. khan, "Efficiency and Performance Analysis of On demand Routing Protocols in Autonomous System", Australian Journal of Basic and Applied Sciences, vol. 5, no. 6, pp: 1619-1631, 2011.

[4] A. Al-Maashri, M. Ould-Khaoua, "Performance analysis of MANET routing protocols in the presence of selfsimilar traffic", In Proceedings of the $31^{\text {st }}$ IEEE Conference on Local Computer Networks, 2006, pp: 801-807.

[5] V. Singla and P. Kakkar,'Traffic pattern based performance comparison of reactive and proactive protocols of mobile ad-hoc networks", International Journal of Computer Applications, vol. 5, no. 10, 2010.
[6] H. Nawaz and H. M. Ali “Analysis of Routing Protocol Metrics in MANET" In Proceedings of $20^{\text {th }}$ National Research Conference Department of Computer Science and engineering, Management Sciences and $20^{\text {th }}$ National Research Conference at SZABIST, 2014.

[7] K. Pandey and A. Swaroop "A Comprehensive Performance Analysis of Proactive, Reactive and Hybrid MANETs Routing Protocols" International Journal of Computer Science Issues, vol. 8, issue 6, no. 3, pp: 432 441, 2011.

[8] M. S. Bhat, D. Shwetha and J. T. Devaraju "A Performance Study of Proactive, Reactive and Hybrid Routing Protocols using Qualnet Simulator" International Journal of Computer Applications, vol. 28, no. 5, pp: 10-17, 2011.

[9] P. Kuppusamy, K. Thirunavukkarasu and B. Kalaavathi "A Study and Comparison of OLSR, AODV and TORA Routing Protocols in Ad Hoc Networks", In Proceedings of $3^{\text {rd }}$ International Conference on Electronics Computer Technology (ICECT), 2011, pp:143-147.

[10] N. Bilandi and H. K. Verma " Comparative Analysis of Reactive and Proactive Routing Protocols in MANETs Using Throughput, Delay and Network Load" International Journal of Advanced and Innovative Research, vol. 1, no. 1, pp: 1-6, 2012.

[11] M. Palaniammal and M. Lalli "Comparative Study of Routing Protocols For Manets" International Journal of Computer Science and Mobile Applications, vol. 2, no. 2, pp: 118-127, 2014.

[12]A. Shrestha and F. Tekiner "On MANET Routing Protocols for Mobility and Scalability" In Proceedings of International Conference on Parallel and Distributed Computing, Applications and Technologies, 2009, pp: 451-456.

[13] S. Shelja and K. Suresh "Performance Improvement of OLSR Protocol by Modifying the Routing Table Construction Mechanism" In Proceedings of International Conference on Reliability, Optimization and Information Technology (ICROIT 2014), 2014, pp: 182-187.

[14] V. Saravanan and D. Vijayakumar "Performance of Reactive and Proactive MANET Routing Protocols with Trajectories" International Journal of Engineering Research \& Technology, vol. 1, no. 8, pp: 1-11, 2012.

[15] M. S. Islam, M. N. Islam, M. S. Alam, M. A. Riaz, and M. T. Hasan "Performance evaluation of various vocoders in Mobile Ad hoc Network (MANET)" In Proceedings of $6^{\text {th }}$ International Conference on Electrical and Computer Engineering December, 2010, pp: 670-673.

[16] S. Gandhi, N. Chaubey, P. Shah and M. Sadhwani "Performance Evaluation of DSR, OLSR and ZRP Protocols in MANETs" In Proceedings of International Conference on Computer Communication and Informatics, 2012.

[17] M. Sharma, N. Kaur and G. Singh "Network traffic based assessment of reactive, proactive and hybrid 
MANET protocols" Journal of Electronics and Communication Engineering, vol. 9, no. 2, pp: 82-86, 2014.

[18] S. Naseer, S. A. Hussain, I. Raza, S. R. Chaudry, J. S. Mirza and M. H. Raza "Mobile Ad-hoc Network Routing Protocols: A Simulation and Performance Analysis Using Multimedia traffic," Journal of Basic and Applied Scientific Research, vol. 2, no. 10, pp: 9925-9930, 2012.

[19]P. Gupta and S. Gupta "Performance Evolution of Mobility Models on MANET Routing Protocols" In Proceedings of Third International Conference on Advanced Computing \& Communication Technologies, 2013, pp: 248-253.

[20] M. A. Mostafavi, A. A. Moghanjoughi and H. Mousavi "A Review and Performance Analysis of Reactive and Proactive Routing Protocols on MANET", Network and Communication Technologies, vol. 1, no. 2, pp: 48-58, 2012.

[21] M. M. Morshed, F. I. S. ko, D. lim and M. H. Rehman "Performance Evaluation of DSDV and AODV Routing
Protocols in Mobile Ad-hoc Networks", In Proceedings of $4^{\text {th }}$ International Conference on New Trends in Information Science and Service Science (NISS), 2010, pp: 399-403

[22] A. Kumar, L. C. Reddy and P. S. Hiremath "Mobile Adhoc Networks: Issues, Research Trends and Experiments", Journal of Communication Techniques, vol. 2, no. 2, pp: 57-63, 2008.

[23] B. D. Shivahare, C. Wahi and S. Shivhare "Comparison of Proactive and Reactive Routing Protocols in Mobile Adhoc Network Using Routing Protocol Property", International Journal of Emerging Technology and Advanced Engineering, vol. 2, no. 3, pp: 356-359, 2012.

[24]H. Kaur and J. Singh "Performance Comparison of OLSR, GRP and TORA using OPNET", International Journal of Advanced Research in Computer Science and Software Engineering, vol. 2, no. 10, pp: 260-267, 2012.

[25]L. M. Duong , L. Zitoune,_and V. Veque,_ “A Medium Access Delay MAC aware metric for Multihop Wireless Networks" In Proceedings of Wireless Communications and Mobile Computing Conference (IWCMC), 2012, pp: 475-480. 